\title{
Effect of reducing $\mathrm{Lu}^{3+}$ content on the fabrication and scintillation
}

\section{properties of non-stoichiometric $\mathrm{Lu}_{3-\mathrm{x}} \mathrm{Al}_{5} \mathrm{O}_{12}$ :Ce ceramics ${ }^{* *}$}

Shuping Liu ${ }^{1,2}$, Jiri A. Mares ${ }^{3}$, Xiqi Feng ${ }^{1}$, Vladimir Babin ${ }^{3}$, Chen $\mathrm{Hu}^{1}$, Huamin Kou ${ }^{1}$, Carmelo D’Ambrosio ${ }^{4}$, Yubai Pan ${ }^{*}, 1$, Martin Nikl ${ }^{*}, 3$

${ }^{1}$ Key Laboratory of Transparent Opto-functional Inorganic Materials, Shanghai Institute of Ceramic, Chinese Academy of Science, 200050 Shanghai, China

${ }^{2}$ University of Chinese Academy of Sciences, 100049 Beijing, China

${ }^{3}$ Institute of Physics v.v.i., AS CR, Cukrovarnicka 10, 16253 Prague, Czech Republic

${ }^{4}$ CERN, PH-LHB group, Geneva 23, CH1211 Switzerland

* Corresponding author: ybpan@mail.sic.ac.cn (Yubai Pan), Phone: +86-21-52412820; nikl@fzu.cz (Martin Nikl), Phone: +420 220318445.

** Results from this paper were presented at $7^{\text {th }}$ International Symposium on Laser, Scintillation and Nonlinear Optical Materials in Lyon, France, 29.2.-4.3.2016 - Jiri A. Mares in Invited Talk I-11 Single crystal and ceramic $(\mathrm{Lu}, \mathrm{Y})$ aluminium garnet materials: Comparative studies of their scintillation properties

\section{Abstract:}

$\mathrm{Lu}_{3-\mathrm{x}} \mathrm{Al}_{5} \mathrm{O}_{12}: \mathrm{Ce}$ optical ceramics $\left(\mathrm{Lu}_{3-\mathrm{x}} \mathrm{AG}: \mathrm{Ce}, \mathrm{x}=1,2,3\right.$ and 4 at. \%, respectively) with $\mathrm{Lu}^{3+}$ compositions ranging from 1 to 4 at. $\%$ below stoichiometry content were fabricated by solid state reaction method and further optimized by an air-annealing process. The effect of $\mathrm{Lu}^{3+}$ deficiency on the optical, luminescence and scintillation properties of such a non-stoichiometric $\mathrm{Lu}_{3-\mathrm{x}} \mathrm{Al}_{5} \mathrm{O}_{12}: \mathrm{Ce}$ ceramics was investigated. Significant influence in the material densification was found leading to strong changes in the transparency, radioluminescence (RL) and scintillation response of these ceramics. Within the range of 1 to 4 at. $\% \mathrm{Lu}^{3+}$ deficiency, $\mathrm{Lu}_{\mathrm{Al}}$ antisite defects were suppressed effectively and the $\mathrm{Lu}_{3-\mathrm{x}} \mathrm{AG}$ :Ce ceramics displayed an extremely 
high RL intensity which reaches $\sim 4$ times higher than that of the latest commercial LuAG:Ce single crystals while its transparency deteriorated. The microstructure, presence of foreign phases and charge traps acting in scintillation mechanism were also characterized by means of SEM, back scattered electron imaging and thermoluminescence techniques, respectively.

Key words: LuAG:Ce ceramics, $\mathrm{Lu}^{3+}$ deficiency, scintillation light yield, non-stoichiometry, antisite defects

\section{Introduction}

Inorganic scintillating crystals are widely used in ionizing radiation detectors in various modern applications as in medical imaging techniques (X-ray computed tomography CT or positron emission tomography PET), homeland security and high energy physics (LHC electromagnetic calorimeters at CERN) [1-5]. Besides scintillating quality criteria as high light yield, fast scintillation response and low afterglow intensity, good scintillator materials should be fabricated with large size, good chemical stability and material uniformity. Thus a number of new excellent scintillators based on $\mathrm{Ce}^{3+}$ and $\mathrm{Pr}^{3+}$-doped materials, together with truly novel nano-scintillator, nano-composite and phase separated material systems, were discovered and studied in depth during the last two decades [6-8]. Optically transparent ceramic materials, which are characterized by lower preparation temperature, more uniform doping and lower cost, are also pushed as an alternative to their single crystal analogs during recent years. 
First reported in 2005, $\mathrm{Ce}^{3+}$ doped $\mathrm{Lu}_{3} \mathrm{Al}_{5} \mathrm{O}_{12}$ (LuAG:Ce) ceramics were fabricated with high transparency by means of solid state sintering technologies $[9,10]$. Later on, flame spray pyrolysis for nanoparticle production followed by cold pressing, vacuum sintering and hot isostatic pressing was used for production of ceramics [11]. Also spark plasma sintering method was used for preparation of both undoped LuAG [12] and Ce-doped LuAG [13]. However, many factors affect the radioluminescence (RL) efficiency and scintillation performance of LuAG:Ce ceramics, including the chemical composition, electronic structure, intrinsic and extrinsic defect states, fabrication techniques and also post-preparation treatments. The light yield (LY) of LuAG:Ce ceramics first reported was only $50 \%$ of that of $\mathrm{Bi}_{4} \mathrm{Ge}_{3} \mathrm{O}_{12}$ (BGO) reference single crystal. At least $75 \%$ of generated light was released at times longer than $1 \mu$ s after excitation and this is due to the occurrence of deep electron traps introduced by using simultaneously traditional sintering aids such as $\left(\mathrm{C}_{2} \mathrm{H}_{5} \mathrm{O}\right)_{4} \mathrm{Si}$ (tetraethyl ortho-silicate, TEOS) and MgO [14]. In 2011, Yanagida et al. accomplished a higher LY in LuAG:Ce ceramics (14800 ph/MeV, 2 ss shaping time) than its single crystal analogous for the first time [15]. In our recent preliminary study, a very high LY (27000 ph/MeV, at $2 \mu$ s and higher shaping times) was achieved in LuAG:Ce,Mg ceramics by using a $\mathrm{Mg}^{2+}$ ion co-doping strategy. Similarly to what occurs in the Ce-doped orthosilicates (LSO, LYSO), we proposed that the stable $\mathrm{Ce}^{4+}$ ions in garnet LuAG:Ce,Mg ceramics can positively participate in the scintillation processes and contribute to fast scintillation response in parallel with stable $\mathrm{Ce}^{3+}$ scintillating centers [8,16-18]. Therefore, scintillators based on LuAG garnet structure (both crystals and 
ceramics) are presently considered as competitive candidates for advanced scintillation applications.

On the other hand, we have also succeeded in fabricating transparent $\mathrm{Lu}^{3+}$ rich non-stoichiometric $\mathrm{Lu}_{3+\mathrm{x}} \mathrm{AG}$ :Ce ceramics without using any traditional sintering aids $[19,20]$. The $\mathrm{RL}$ efficiency of the best $\mathrm{Lu}^{3+}$ rich $\mathrm{Lu}_{3+\mathrm{x}} \mathrm{AG}$ :Ce ceramic is about 2.5 times higher than of that of the LuAG:Ce, $\mathrm{Mg}$ ceramics above mentioned. Unfortunately, the presence of $\mathrm{Lu}_{\mathrm{Al}}$ antisite defects (AD)-related shallow electron traps were observed in these ceramics by RL and thermoluminescence (TSL) measurements. As a result, a degraded scintillation performance including higher slow decay components and higher afterglow intensities was obtained. Since the fabrication temperature of LuAG:Ce ceramics is lower than that of single crystal analogue and no material melting occurs along the preparation route in the former, it seems easier to suppress the formation of $\mathrm{Lu}_{\mathrm{Al}} \mathrm{AD}$ in ceramics. Thus $\mathrm{LuAG}$ :Ce ceramic with $\mathrm{Lu}^{3+}$ deficiency should be considered as promising material to be $\mathrm{AD}$ free with an improved scintillation performance.

Therefore, this paper deals with luminescence (radioluminescence), scintillation properties and also characterization of defects of $\mathrm{Lu}^{3+}$ deficient non-stoichiometric $\mathrm{Lu}_{3-\mathrm{x}} \mathrm{AG}$ :Ce ceramics. Optical absorption, RL spectra, TSL glow curves, scintillation characteristics including light yield, scintillation decay, afterglow intensity and also the microstructure of the ceramics were measured to reveal systematically the influence of stoichiometric deviation. The discussion on the composition and 
properties tailoring includes a comparative study with 1 at. $\% \mathrm{Lu}^{3+}$ excess $\mathrm{Lu}_{3+1} \% \mathrm{AG}:$ Ce ceramics and the latest commercial LuAG:Ce single crystal.

\section{Experimental}

We denote the $\mathrm{Lu}^{3+}$ deficient non-stoichiometric lutetium garnet ceramics as $\mathrm{Lu}_{3-\mathrm{x}} \mathrm{AG}: \mathrm{Ce}(\mathrm{x}=1,2,3$ and 4 at. $\%)$. These ceramics were fabricated by solid state reaction method and further optimized by an air-annealing process. Commercial powders of $4 \mathrm{~N}$ purity $\mathrm{CeO}_{2}$ and $\alpha-\mathrm{Al}_{2} \mathrm{O}_{3}$ were weighted according to the chemical stoichiometry of $\left(\mathrm{Lu}_{1-\mathrm{y}} \mathrm{Ce}_{\mathrm{y}}\right)_{3} \mathrm{Al}_{5} \mathrm{O}_{12}$, where $\mathrm{y}=0.003$, while commercial $\mathrm{Lu}_{2} \mathrm{O}_{3}$ powders of $4 \mathrm{~N}$ purity were weighted with $1,2,3$ and 4 wt. $\%$ in deficiency accordingly. After being vacuum sintered at $1880^{\circ} \mathrm{C}$ for $30 \mathrm{~h}$ and air-annealed at 1450 ${ }^{\circ} \mathrm{C}$ for $20 \mathrm{~h}$, all the samples were double-polished to a thickness of $0.5-1 \mathrm{~mm}$ for measurements. In order to clarify the effect of $\mathrm{Lu}^{3+}$ content, 1 at. $\% \mathrm{Lu}^{3+}$ rich $\mathrm{Lu}_{3+1 \%} \mathrm{AG}: 0.5 \% \mathrm{Ce}$ non-stoichiometric ceramic sample prepared under the same conditions was used for comparison [19]. The detailed technological route has already been described in our previous works $[19,20]$. However, the stoichiometric LuAG:Ce ceramic is lacking in the sample set because high quality stoichiometric LuAG:Ce ceramic could not be fabricated successfully under the same condition without using traditional sintering aids. A commercial LuAG:Ce single crystal grown by Czochralski method (by Crytur Ltd., Turnov, Czech Republic), as well as a Bridgman grown BGO single crystal provided either by SICCAS Corp. (Shanghai, China) or obtained from M. Ishii (Shonan Institute of Technology, Japan) were used as 
reference samples.

Absorption spectra in the $200-800 \mathrm{~nm}$ range were measured using a Varian Cary 5000 spectrometer (Varian Inc., USA). The microstructure of the ceramics was observed with a S-4800 field emission scanning electron microscope (SEM, Hitachi, Japan). RL spectra were measured under an X-ray tube excitation (Seifert $\mathrm{GmbH}$, Germany, $40 \mathrm{kV}, 15 \mathrm{~mA}$ ) at the custom-made 5000M model Horiba Jobin Yvon fluorometer (Horiba Jobin Yvon, Co., France) equipped with a TXB-04 photon counting detector. For afterglow measurements, samples were irradiated by X-rays with the same X-ray tube (operated at $40 \mathrm{kV}$ ) at RT, after which the beam was cut off and the luminescence emitted from samples was recorded immediately as a function of time. TSL measurements were performed in the 77-500 K temperature range in the cryostat Optistat (Oxford Instruments) after x-ray irradiation at $77 \mathrm{~K}$ (operated at 40 $\mathrm{kV}$ for 15 minutes). A $5 \mathrm{~K} / \mathrm{min}$ heating rate was adopted.

Scintillation light yields were measured using hybrid photodetectors (HPMT hybrid photomultipliers DEP PP0470 or PP0475B ones, DEP, Netherlands) [21]. Light yields (LY) as a function of the energy $\mathrm{E}$ were evaluated from photoelectron yields $\mathrm{N}_{\text {phels }}(\mathrm{E})$ by using of calibrated quantum efficiency (Q.E.) of HPMT's and emission spectra of scintillators. Measured ceramics are characterized by wide emission bands peaking in the green range where Q.E. is around or below $10 \%$ but due to Q.E. calibration and precise measurements of radioluminescence an accuracy of L.Y. measurements is \pm 5\%. Scintillation decay curves were obtained by using the Hamamatsu PMT R375 (Hamamatsu Co., Japan) and TDS3052 digital oscilloscope (Tektronix Inc., USA) 
under excitation by $662 \mathrm{keV} \gamma$-ray photons of ${ }^{137} \mathrm{Cs}$ source. To enhance collection of scintillation photons a teflon reflection tape was used to cover the measured samples. Good optical coupling between samples and HPMT photocathode window was ensured by Q2-3067 optical grease (Dow Corning Co., USA).

\section{Results and Discussion}

\subsection{Absorption spectra}

Fig. 1 shows the absorption spectra of the air-annealed $\mathrm{Lu}^{3+}$-deficient $\mathrm{Lu}_{3-\mathrm{x}} \mathrm{AG}: \mathrm{Ce}$ ceramics. In the inset there are photographs of selected samples. The broad absorption bands at about 450 and $350 \mathrm{~nm}$ are related to the $\mathrm{Ce}^{3+} 4 f \rightarrow 5 d_{1}$ and $5 d_{2}$ transitions, respectively. The absorption pattern below $300 \mathrm{~nm}$ is composite due to the overlap of higher $4 \mathrm{f} \rightarrow 5 \mathrm{~d} \mathrm{Ce}^{3+}$ absorption bands, $\mathrm{Ce}^{4+}$ charge transfer absorption band and various intrinsic and trace-impurity $\left(\mathrm{Fe}^{2+}, \mathrm{Yb}^{2+}\right)$ related absorption [22-24]. The additional absorption band peaking at $240 \mathrm{~nm}$ is reported as due to the charge transfer absorption of $\mathrm{Ce}^{4+}$ centers [25]. Its occurrence is reasonable because some part of the $\mathrm{Ce}^{3+}$ ions would be oxidized to $\mathrm{Ce}^{4+}$ state during the air annealing process which was performed to diminish the concentration of oxygen vacancies produced in the vacuum sintering process. Since $\mathrm{Lu}^{3+}$ deficient $\mathrm{Lu}_{3-\mathrm{x}} \mathrm{AG}$ :Ce ceramics displayed a poor optical quality, the presence of scattering centers leads to a higher constant absorption in the visible region. When compared to the optical qualities of $\mathrm{Lu}^{3+}$ rich $\mathrm{Lu}_{3+\mathrm{x}} \mathrm{AG}$ :Ce ceramics we reported before, it indicates again that excess of $\mathrm{Lu}^{3+}$ could act as "self-sintering aid" in the fabrication process of LuAG:Ce ceramics [19]. 


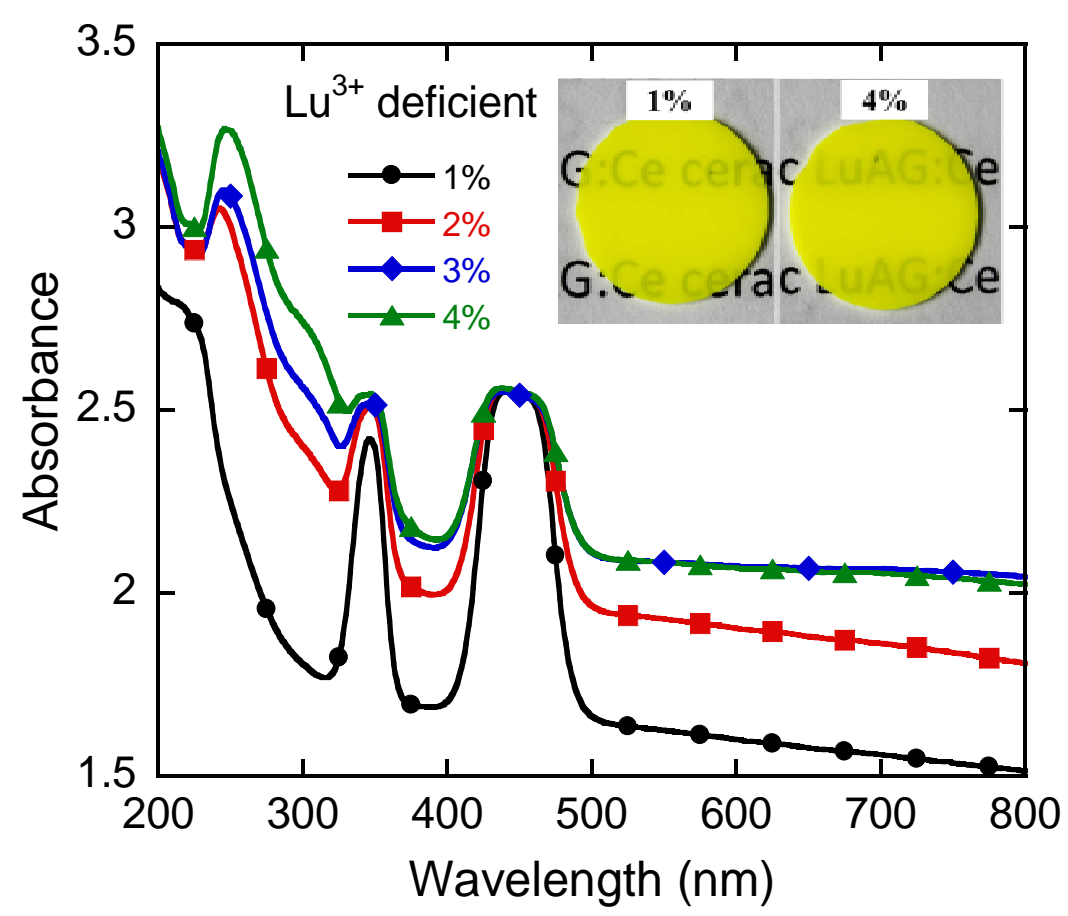

Fig. 1 Optical absorption spectra of $\mathrm{Lu}^{3+}$ deficient non-stoichiometric $\mathrm{Lu}_{3-\mathrm{x}} \mathrm{AG}$ :Ce ceramics with various $\mathrm{Lu}^{3+}$ content (cut-off of the the $4 \mathrm{f} \rightarrow 5 \mathrm{~d}_{1}$ absorption band of $\mathrm{Ce}^{3+}$ centers peaking at $\sim 450 \mathrm{~nm}$ is an experimental artifact). In the inset there are photographs of corresponding samples.

\subsection{Radioluminescence spectra}

In Fig. 2a, the RL spectra of the air-annealed $\mathrm{Lu}^{3+}$ deficient non-stoichiometric $\mathrm{Lu}_{3-\mathrm{x}} \mathrm{AG}: \mathrm{Ce}$ ceramics are displayed together with those of the $1 \% \mathrm{Lu}^{3+}$ rich $\mathrm{Lu}_{3+1 \%} \mathrm{AG}$ :Ce ceramic and the LuAG:Ce reference single crystal. The composition dependent RL intensities (spectrum integrals in the $440-740 \mathrm{~nm}$ region related to $\mathrm{Ce}^{3+}$ emission) are shown in Fig. 2b. Unlike $\mathrm{Lu}^{3+}$ rich $\mathrm{Lu}_{3+\mathrm{x}} \mathrm{AG}$ :Ce ceramic and LuAG:Ce single crystal, $\mathrm{Lu}_{\mathrm{Al}} \mathrm{AD}$ related luminescence in the $\mathrm{UV}$ region can be hardly detected in $\mathrm{Lu}^{3+}$ deficient $\mathrm{Lu}_{3-\mathrm{x}} \mathrm{AG}$ :Ce ceramics, see the inset of Fig. $2 \mathrm{a}$. It means that the formation of $\mathrm{Lu}_{\mathrm{Al}} \mathrm{AD}$ can be suppressed effectively as we expected by decreasing the 
content of $\mathrm{Lu}^{3+}$ in LuAG:Ce ceramics. Therefore, $\mathrm{Lu}^{3+}$ deficient $\mathrm{Lu}_{3-\mathrm{x}} \mathrm{AG}$ :Ce ceramics show a remarkable higher RL efficiency than $\mathrm{Lu}^{3+}$ rich ones, reaching 4 times of that of the high quality commercial LuAG:Ce single crystal. We note that this quantitative comparison might be influenced by the lowered transparency of the Lu-deficient samples.
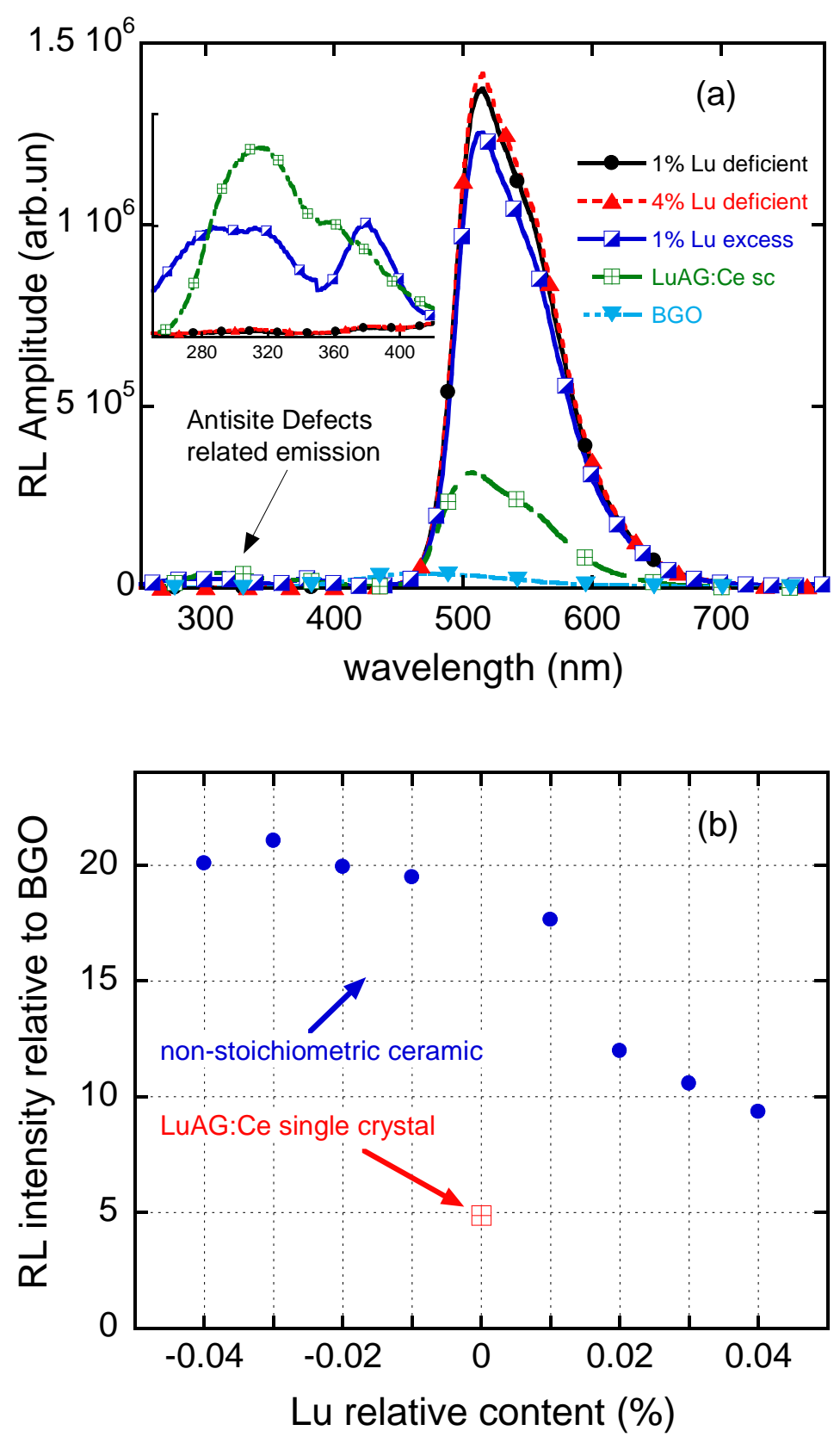

Fig. 2 (a) Absolute scale comparison of RL spectra of the $\mathrm{Lu}^{3+}$ deficient and $\mathrm{Lu}^{3+}$ rich 
non-stoichiometric $\mathrm{Lu}_{3 \pm x} \mathrm{AG}$ :Ce ceramics; (b) RL intensity of the ceramics versus $\mathrm{Lu}^{3+}$ relative contents. The data of LuAG:Ce reference single crystal were also reported as comparison.

\subsection{Scintillation properties}

Similarly to RL intensity, a clear improved scintillation performance is observed in $\mathrm{Lu}^{3+}$ deficient $\mathrm{Lu}_{3-\mathrm{x}} \mathrm{AG}$ :Ce ceramics. As is shown in Fig. 3 and Table 1, the LY of fast parts of decays (below or around $1 \mu \mathrm{s}$ ) of $\mathrm{Lu}^{3+}$ deficient $\mathrm{Lu}_{3-1 \%} \mathrm{AG}$ :Ce ceramic is higher than that of $1 \%$ rich $\mathrm{Lu}^{3+} \mathrm{Lu}_{3+1} \mathrm{AG}$ :Ce ceramic and the commercial $\mathrm{BGO}$ single crystal. LY of $\sim 18000 \mathrm{ph} / \mathrm{MeV}$ was obtained in $1 \% \mathrm{Lu}^{3+}$ deficient $\mathrm{Lu}_{3-1 \%} \mathrm{AG}$ :Ce ceramic (measured with $1 \mu$ s shaping time) which is higher than that of the commercial LuAG:Ce single crystal where the LY obtained was $16390 \mathrm{ph} / \mathrm{MeV}$ (see Table 1). However, the light yield of $\mathrm{Lu}^{3+}$ deficient $\mathrm{Lu}_{3-1 \%} \mathrm{AG}$ :Ce ceramic becomes lower than that of the LuAG:Ce sigle crystal when the shaping time is longer than $2 \mu$ s (see Fig. 3). Fig. 4 shows the scintillation decay curves of the ceramics and the LuAG:Ce single crystal. The double exponential fit of the decay curves was accomplished and the results are included in Table 1. All the samples show scintillation decays consisting of two components and these ones are due to the prompt and delayed radiative recombination at $\mathrm{Ce}^{3+}$ centers. But it is clear that the $\mathrm{Lu}^{3+}$ deficient $\mathrm{Lu}_{3-\mathrm{x}} \mathrm{AG}: \mathrm{Ce}$ ceramics exhibit faster decays compared to the $\mathrm{Lu}^{3+}$ rich one and the LuAG:Ce single crystal (between 56-59 ns and around $70 \mathrm{ns,}$ respectively). Furthermore, the relative weight of fast scintillation decay component is 
only $~ 41 \%$ in $\mathrm{Lu}^{3+}$ rich $\mathrm{Lu}_{3+\mathrm{x}} \mathrm{AG}: \mathrm{Ce}$ ceramic and $~ 34 \%$ in LuAG:Ce single crystal, while in $\mathrm{Lu}^{3+}$ deficient $\mathrm{Lu}_{3-\mathrm{x}} \mathrm{AG}: \mathrm{Ce}$ ceramic it increases up to $\sim 50 \%$. All the improved scintillation performance could be ascribed to the suppression of $\mathrm{Lu}_{\mathrm{Al}} \mathrm{AD}$ defects and related traps. Consequently, in microsecond time scale, the energy transfer from the host to the $\mathrm{Ce}^{3+}$ centers significantly accelerated in $\mathrm{Lu}^{3+}$ deficient $\mathrm{Lu}_{3-\mathrm{x}} \mathrm{AG}:$ Ce ceramics $[26,27]$.

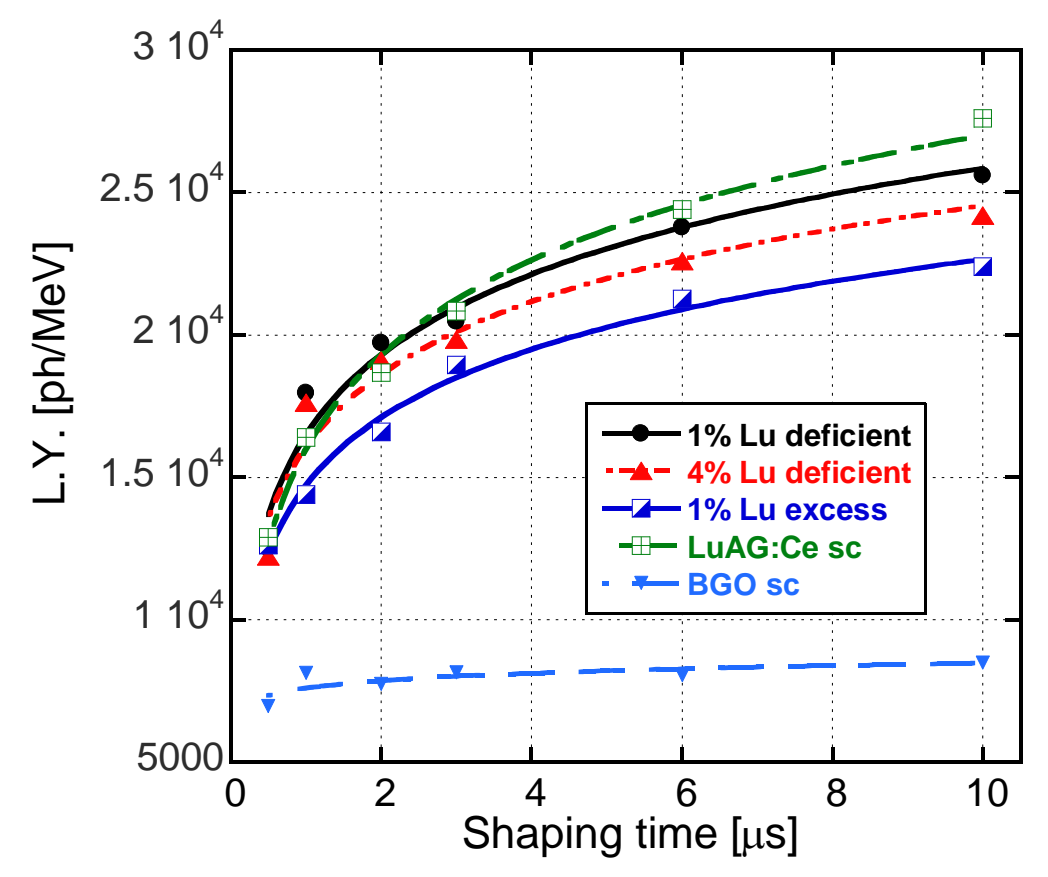

Fig. 3 Light yields of $\mathrm{Lu}^{3+}$ deficient and $1 \% \mathrm{Lu}^{3+}$ rich non-stoichiometric $\mathrm{Lu}_{3 \pm x} \mathrm{AG}: \mathrm{Ce}$ ceramics and LuAG:Ce single crystal as a function of shaping time in the $0.5-10 \mu \mathrm{s}$ range.

Table 1. Sample characteristics, light yield values and scintillation decay constants (excitation by $662 \mathrm{keV}$ energy of ${ }^{137} \mathrm{Cs}$ of the $\mathrm{Lu}^{3+}$ deficient non-stoichiometric $\mathrm{Lu}_{3-\mathrm{x}} \mathrm{AG}: \mathrm{Ce}$ ceramics, the $1 \% \mathrm{Lu}^{3+}$ rich $\mathrm{Lu}_{3+1} \mathrm{AG}: \mathrm{Ce}$ one and the LuAG:Ce single crystal. A double-exponential function $I(t)=\sum A_{i} \exp \left[-t / \tau_{i}\right] \mathrm{i}=1,2$ is used to fit the 
scintillation decay curves. The relative intensities of each component $I_{i}=A_{i} \tau_{i} /$ $\sum A_{j} \tau_{j} \times 100(i, j=1,2)$ are also reported.

\begin{tabular}{lccccc}
\hline Samples & $\begin{array}{c}\text { Size } \\
(\mathrm{mm})\end{array}$ & $\begin{array}{c}\mathrm{LY}_{1 \mu \mathrm{s}} \\
(\mathrm{ph} / \mathrm{MeV})\end{array}$ & $\begin{array}{c}\mathrm{LY}_{10 \mu \mathrm{s}} \\
(\mathrm{ph} / \mathrm{MeV})\end{array}$ & $\tau_{1}(\mathrm{~ns}) / \mathrm{I}_{1}(\%)$ & $\tau_{2}(\mathrm{~ns}) / \mathrm{I}_{2}(\%)$ \\
\hline Lu deficient-1 \% & $\varnothing 15 \times 1$ & 18000 & 25610 & $59 / 48$ & $1230 / 52$ \\
Lu deficient-4 \% & $\varnothing 15 \times 1$ & 17600 & 24200 & $56 / 50$ & $1140 / 50$ \\
Lu rich-1\% & $\varnothing 15 \times 1$ & 14400 & 22400 & $69 / 41$ & $1120 / 59$ \\
LuAG:Ce sc & $\varnothing 10 \times 1$ & 16390 & 27600 & $70 / 34$ & $1700 / 66$ \\
\hline
\end{tabular}

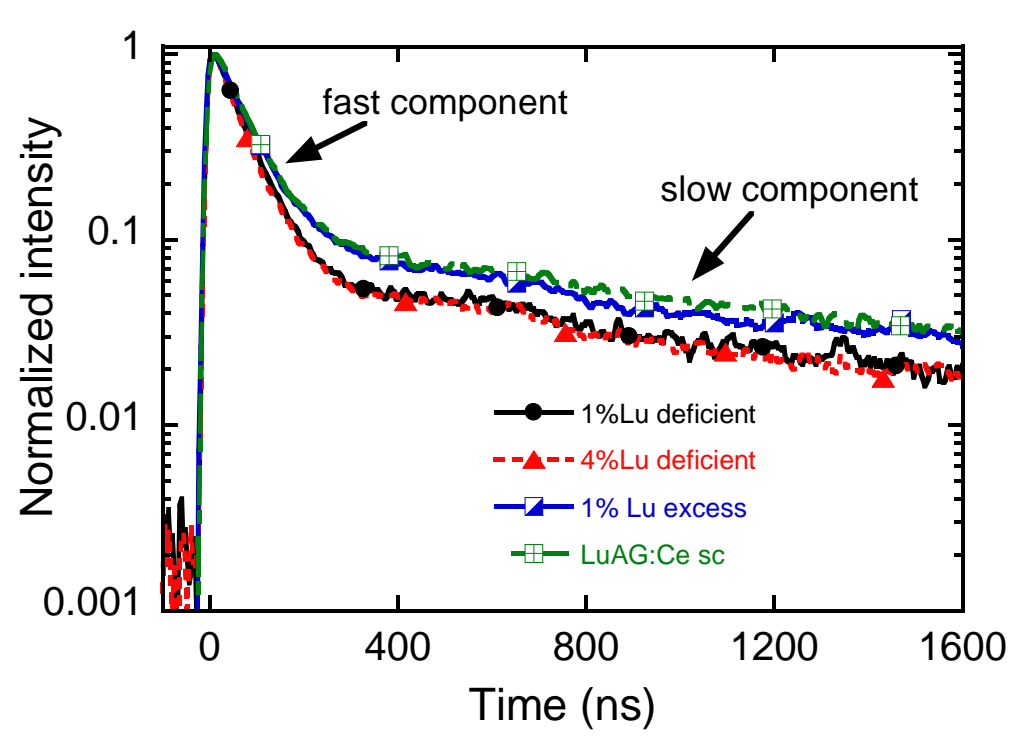

Fig. 4. Normalized scintillation decay curves of $\mathrm{Lu}^{3+}$ deficient and $\mathrm{Lu}^{3+}$ rich non-stoichiometric $\mathrm{Lu}_{3 \pm x} \mathrm{AG}: \mathrm{Ce}$ ceramics and the reference LuAG:Ce single crystal.

In Fig. 5, the afterglow characteristics of $\mathrm{Lu}^{3+}$ deficient and $\mathrm{Lu}^{3+}$ rich non-stoichiometric $\mathrm{Lu}_{3 \pm x} \mathrm{AG}: \mathrm{Ce}$ ceramics and LuAG:Ce single crystal are shown together with BGO reference single crystal, which is known by its extremely low afterglow. Apparently, the $\mathrm{Lu}^{3+}$ deficient non-stoichiometric $\mathrm{Lu}_{3-\mathrm{x}} \mathrm{AG}$ :Ce ceramics show much lower afterglow intensities when compared to the $1 \% \mathrm{Lu}^{3+}$ rich one. This result is consistent with the higher $\mathrm{RL}$ intensities and light yields in the $\mathrm{Lu}^{3+}$ deficient 
$\mathrm{Lu}_{3-\mathrm{x}} \mathrm{AG}$ :Ce ceramics in Fig. 2 and Table 1. However, when compared with LuAG:Ce single crystal, the $\mathrm{Lu}_{3-\mathrm{x}} \mathrm{AG}: \mathrm{Ce}$ ceramics show somewhat worse afterglow characteristics which suggests that there should be some deep traps located in the ceramic which play a key role in delaying the carrier transport stage towards $\mathrm{Ce}^{3+}$ centers in millisecond time scale during the scintillation process [28].

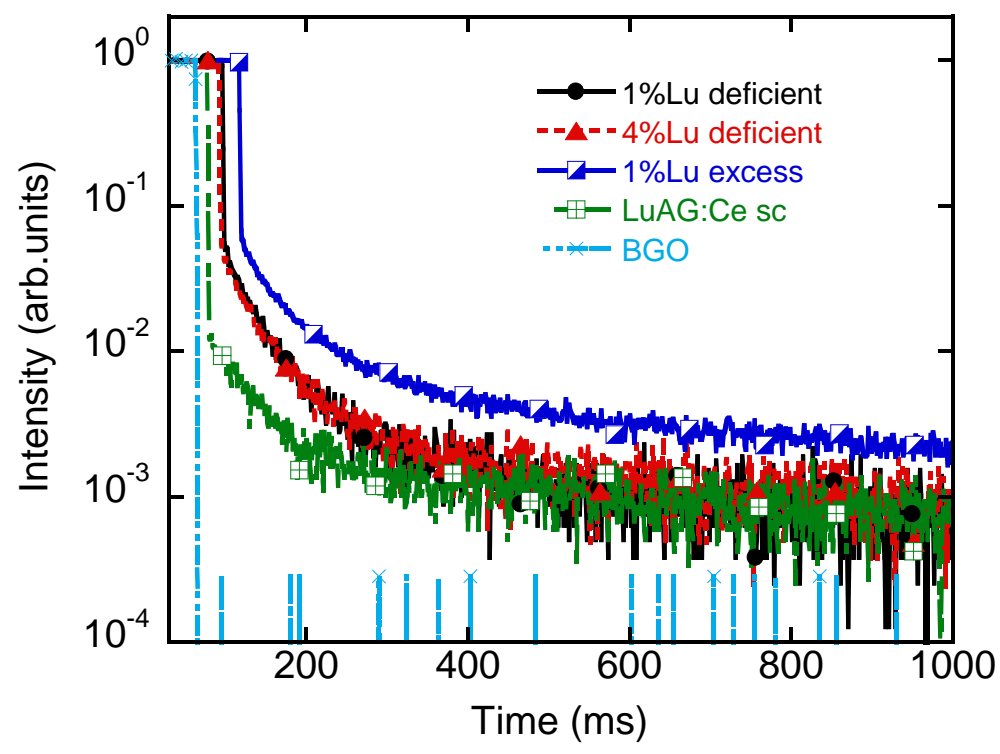

Fig. 5 Spectrally unresolved afterglow time profiles of $\mathrm{Lu}^{3+}$ deficient and $\mathrm{Lu}^{3+}$ rich non-stoichiometric $\mathrm{Lu}_{3 \pm x} \mathrm{AG}: \mathrm{Ce}$ ceramics, $\mathrm{BGO}$ and LuAG:Ce single crystals after the $40 \mathrm{kV}$ X-ray excitation cut-off.

\subsection{Microstructure and role of defects}

As we demonstrated in Fig. 1, the $\mathrm{Lu}^{3+}$ deficient $\mathrm{Lu}_{3-\mathrm{x}} \mathrm{AG}: \mathrm{Ce}$ ceramics are translucent and the scattering phenomena becomes more severe with decreasing the $\mathrm{Lu}^{3+}$ content. To investigate the defects and the effect of $\mathrm{Lu}^{3+}$ deviation from stoichiometry on the densification of the ceramics, the SEM and the back scattered electron imaging of the fracture microstructure of the $\mathrm{Lu}^{3+}$ deficient $\mathrm{Lu}_{3-\mathrm{x}} \mathrm{AG}$ :Ce 
ceramics were performed. The back scattered electron imaging of the fracture microstructure of the ceramics with various content of $\mathrm{Lu}^{3+}$ are shown in Fig. 6. Many residual micropores and the second phase impurities are found, both in the grain boundaries and the host lattice, in all the samples of the $\mathrm{Lu}^{3+}$ deficient ceramics. Their concentrations clearly increase with decreasing $\mathrm{Lu}^{3+}$ content (see Fig. 6). Fig. 7 shows the energy dispersive spectra and the analysis results of the second phase impurities in $4 \% \mathrm{Lu}^{3+}$ deficient $\mathrm{Lu}_{3-4 \%} \mathrm{AG}: \mathrm{Ce}$ non-stoichiometric ceramics. It comes out that there are $\mathrm{Al}_{2} \mathrm{O}_{3}$ or Al-rich compounds which segregated when content of $\mathrm{Lu}^{3+}$ ions in LuAG:Ce is lower than its stoichiometric content. This is consistent with the recent finding in the Yttrium-deficient YAG ceramic [29].
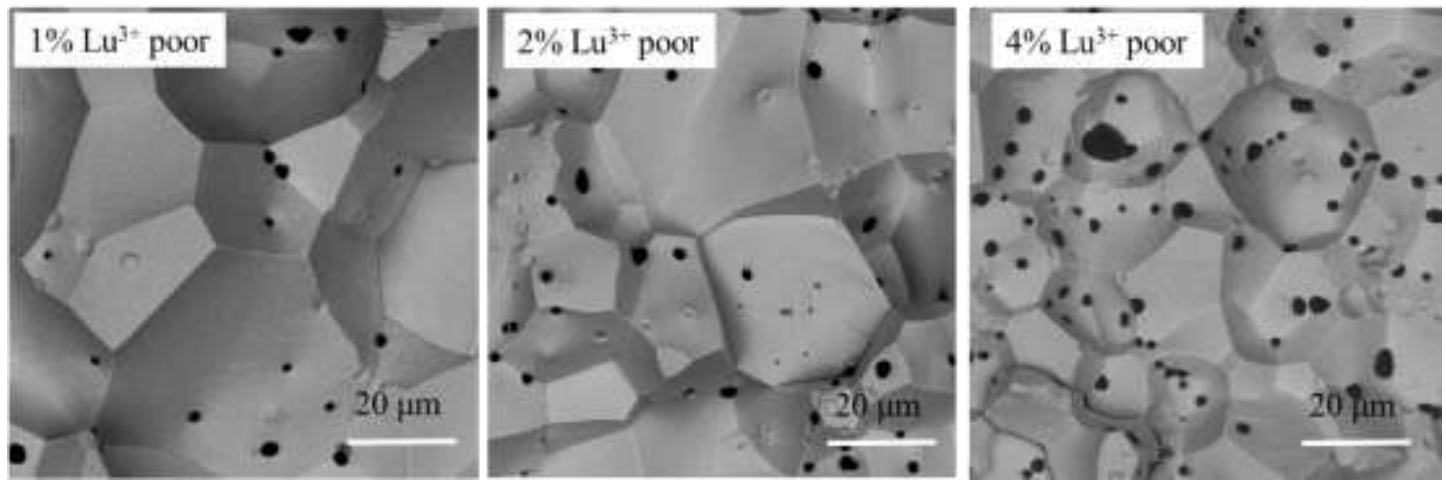

Fig. 6. Back scattered electron imaging of the fracture microstructure of the $\mathrm{Lu}^{3+}$ deficient $\mathrm{Lu}_{3-\mathrm{x}} \mathrm{AG}: \mathrm{Ce}$ ceramics.
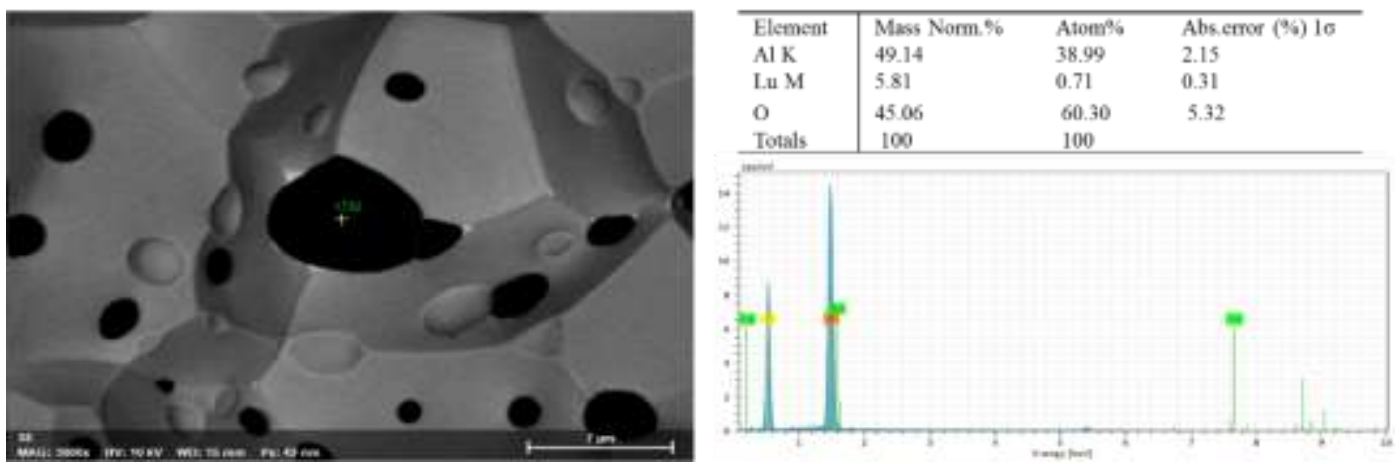

Fig. 7. Energy dispersive spectra of the second phase impurities in $4 \% \mathrm{Lu}^{3+}$ deficient 
$\mathrm{Lu}_{3-4 \%} \mathrm{AG}:$ Ce non-stoichiometric ceramic.

Finally, TSL measurements were carried out with the aim to visualize the role of shallow and deep traps in the RL, scintillation LY and decays, and afterglow characteristics described above. The TSL glow curves in the 77-500 K temperature range are reported in Fig. 8. As seen in Fig. 8, there is relative lack of TSL signal within $150-190 \mathrm{~K}$. It points to the absence of AD-related traps which have TSL signature in this temperature region [30] and is thus consistent with the above described results as for RL spectra, scintillation light yield and decays. The origin of broad TSL band below $150 \mathrm{~K}$ is not clear as its shape is different from that observed in TSL characteristics of LuAG:Ce [30] or LuAG:Pr [31] single crystals. It might be related to shallow traps due to disorder in the interface regions with the foreign phase inclusions mentioned above. The dominating peak at about $240 \mathrm{~K}$ and another two ones above room temperature reasonably coincide with similar peaks observed in LuAG:Ce and LuAG:Pr single crystals [31,32] and related trap centers probably include oxygen vacancy [33]. TSL peaks above room temperature and related traps usually play the role in radiation damage mechanism [34] and in general can further contribute to LY loss. 


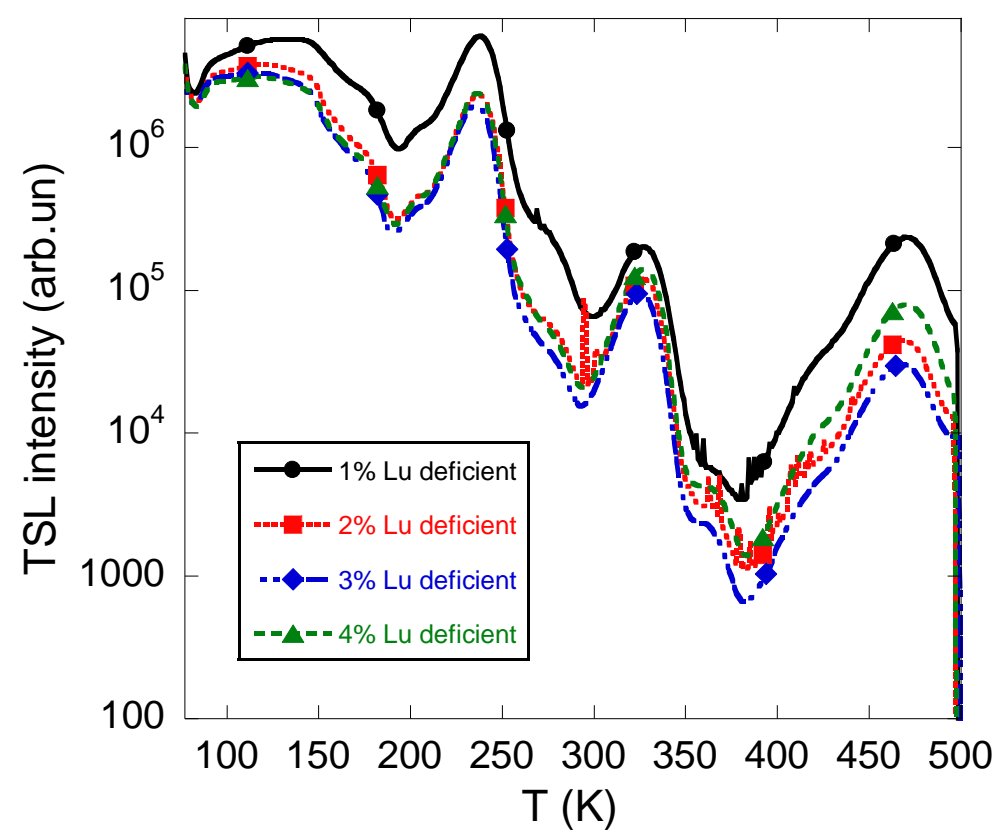

Fig. 8. Spectrally unresolved TSL glow curves of the $\mathrm{Lu}^{3+}$ deficient $\mathrm{Lu}_{3-\mathrm{x}} \mathrm{AG}$ :Ce ceramics. Samples were irradiated for $15 \mathrm{~min}$ by $\mathrm{X}$-ray tube at $77 \mathrm{~K}(40 \mathrm{kV}, 15 \mathrm{~mA})$ before TSL signal collection.

\section{Conclusions}

The $\mathrm{Lu}^{3+}$ deficient non-stoichiometric $\mathrm{Lu}_{3-\mathrm{x}} \mathrm{AG}$ :Ce ceramics $(\mathrm{x}=1,2,3$ and 4 at. \%, respectively) were fabricated by solid state reaction method and further optimized by an air-annealing process. We show that such modification of the composition stoichiometry drastically worsen the optical quality and somewhat improves RL intensity and scintillation response of the ceramics. Reported results in this composition range deepen the comprehension of LuAG:Ce ceramic systems. Within 1 to 4 at. $\% \mathrm{Lu}^{3+}$ deficiency range, the $\mathrm{Lu}_{3-\mathrm{x}} \mathrm{AG}$ :Ce ceramics display an extremely high RL intensity which is $\sim 4$ times higher than that of the high quality commercial LuAG:Ce single crystal and a light yield of about $18000 \mathrm{ph} / \mathrm{MeV}$ with short $1 \mu \mathrm{s}$ 
shaping time. By comparing light yield values with different shaping times and scintillation decays, it turns out that $\mathrm{Lu}_{3-\mathrm{x}} \mathrm{AG}$ :Ce ceramics display a more intense and faster scintillation response than isostructural single crystals commercially available. However, due to the occurrence of Al-rich second phase impurities and other materials defects, the optical quality of these ceramics is degraded and further work is needed to improve it.

\section{Acknowledgements}

The authors gratefully acknowledge the financial support from China Scholarship Council (CSC). This work was supported by the National Science Foundation of China (No. U1332202, 61475175 , 51172262), the Research Program and International Cooperation Program of Shanghai Sciences and Technology Commission Foundation (No. 13JC1405800, 15520721000), and Chinese Academy of Sciences Visiting Professor for Senior International Scientists (Grant No. 2013T2G0004 and No. 2014VTB009). Partial support of Czech Science Foundation project P204/12/0805 is also gratefully acknowledged. Authors are also grateful for useful discussions and suggestions from Prof. Anna Vedda.

\section{References}

[1] M. Nikl, A. Yoshikawa, Recent R\&D Trends in Inorganic Single-Crystal Scintillator Materials for Radiation Detection, Adv. Opt. Mater., 3 (2015) 463-481.

[2] I.H. Campbell, B.K. Crone, Quantum-Dot/Organic Semiconductor Composites for Radiation Detection, Adv. Mater., 18 (2006) 77-79.

[3] O. Sidletskiy, A. Vedda, M. Fasoli, S. Neicheva, A. Gektin, Crystal Composition 
and Afterglow in Mixed Silicates: The Role of Melting Temperature, Phys. Rev. Applied 4 (2015) 024009-1 - 024009-9.

[4] P. Lecoq, A. Annenkov, A. Gektin, M. Korzhik, C. Pedrini, Inorganic scintillators for detector systems: Physical principles and crystal engineering, Springer Verlag, Berlin, Germany 2006.

[5] N. Yasui, Y. Ohashi, T. Kobayashi, T. Den, Development of phase-separated scintillators with light-guiding properties, Adv. Mater. 24 (2012) 5464-5469.

[6] F.P. Doty, C.A. Bauer, A.J. Skulan, P.G. Grant, M.D. Allendorf, Scintillating Metal-Organic Frameworks: A New Class of Radiation Detection Materials, Adv. Mater. 21 (2009) 95-101.

[7] M.A. Spurrier, P. Szupryczynski, K. Yang, A.A. Carey, C.L. Melcher, Effects of $\mathrm{Ca}^{2+}$ co-doping on the scintillation properties of LSO:Ce, IEEE Trans. Nucl. Sci. 55 (2008) 1178-1182.

[8] S. Liu, X. Feng, Z. Zhou, M. Nikl, Y. Shi, Y. Pan, Effect of $\mathrm{Mg}^{2+}$ co-doping on the scintillation performance of LuAG:Ce ceramics, phys. status solidi - Rapid Res. Lett. 8 (2014) 105-109.

[9] H.L. Li, X.J. Liu, L.P. Huang, Fabrication of transparent cerium-doped lutetium aluminum garnet (LuAG : Ce) ceramics by a solid-state reaction method, J. Amer. Ceram. Soc. 88 (2005) 3226-3228.

[10] H.-L. Li, X.-J. Liu, R.-J. Xie, Y. Zeng, L. Ping Huang, Fabrication of Transparent Cerium-Doped Lutetium Aluminum Garnet Ceramics by Co-Precipitation Routes, J. Amer. Ceram Soc. 89 (2006) 2356-2358.

[11] J.D. Kuntz, J.J. Roberts, M. Hough, N.J. Cherepy, Multiple synthesis routes to transparent ceramic lutetium aluminum garnet, Scripta Materialia 57 (2007) 960-963. [12] L. An, A. Ito, T. Goto, Effect of sintering temperature on the transparency and mechanical properties of lutetium aluminum garnet fabricated by spark plasma sintering, J. European Ceram. Soc. 32 (2012) 3097-3102.

[13] J. Pejchal, V. Babin, A. Beitlerova, R. Kucerkova, D. Panek, J. Barta, V. Cuba, A. Yamaji, S. Kurosawa, E. Mihokova, A. Ito, T. Goto, M. Nikl, A. Yoshikawa, Luminescence and scintillation properties of $\mathrm{Lu}_{3} \mathrm{Al}_{5} \mathrm{O}_{12}$ nanoceramics sintered by SPS 
method, Opt. Mater. 53 (2016) 54-63.

[14] M. Nik1, J.A. Mares, N. Solovieva, H.-L. Li, X.-J. Liu, L.-P. Huang, I. Fontana, M. Fasoli, A. Vedda, C. D'Ambrosio, Scintillation characteristics of $\mathrm{Lu}_{3} \mathrm{Al}_{5} \mathrm{O}_{12}$ : $\mathrm{Ce}$ optical ceramics, J. Appl. Phys. 101 (2007).

[15] T. Yanagida, Y. Fujimoto, Y. Yokota, K. Kamada, S. Yanagida, A. Yoshikawa, H. Yagi, T. Yanagitani, Comparative study of transparent ceramic and single crystal Ce doped LuAG scintillators, Rad. Measur. 46 (2011) 1503-1505.

[16] M. Nikl, K. Kamada, V. Babin, J. Pejchal, K. Pilarova, E. Mihokova, A. Beitlerova, K. Bartosiewicz, S. Kurosawa, A. Yoshikawa, Defect Engineering in Ce-Doped Aluminum Garnet Single Crystal Scintillators, Cryst. Growth \& Des. 14 (2014) 4827-4833.

[17] S. Blahuta, A. Bessiere, B. Viana, P. Dorenbos, V. Ouspenski, Evidence and Consequences of $\mathrm{Ce}^{4+}$ in LYSO:Ce, Ca and LYSO:Ce, Mg Single Crystals for Medical Imaging Applications, IEEE Trans. Nucl. Sci., 60 (2013) 3134-3141.

[18] Y.D. Zavartsev, S.A. Koutovoi, A.I. Zagumennyi, Czochralski growth and characterisation of large $\mathrm{Ce}^{3+}: \mathrm{Lu}_{2} \mathrm{SiO}_{5}$ single crystals co-doped with $\mathrm{Mg}^{2+}$ or $\mathrm{Ca}^{2+}$ or $\mathrm{Tb}^{3+}$ for scintillators, J.Cryst. Growth 275 (2005) E2167-E2171.

[19] S. Liu, X. Feng, M. Nikl, L. Wu, Z. Zhou, J. Li, H. Kou, Y. Zeng, Y. Shi, Y. Pan, Fabrication and Scintillation Performance of Nonstoichiometric LuAG:Ce Ceramics, J. Amer. Ceram.Soc. 98 (2015) 510-514.

[20] S. Liu, X. Feng, J.A. Mares, V. Babin, M. Nikl, A. Beitlerova, Y. Shi, Y. Zeng, Y. Pan, C. D’Ambrosio, Y. Huang, Optical, luminescence and scintillation characteristics of non-stoichiometric LuAG:Ce ceramics, J. Lumin. 169, Part A (2016) 72-77.

[21] J.A. Mares, A. Beitlerova, P. Prusa, K. Blazek, P. Horodysky, K. Kamada, A. Yoshikawa, C. D'Ambrosio, M. Nikl, Energy resolution studies of Ce- and Pr-doped aluminum and multicomponent garnets: The escape and photo-peaks, J. Lumin. 169 (2016) 701-705.

[22] Y. Dong, G. Zhou, J. Xu, G. Zhao, F. Su, L. Su, H. Li, J. Si, X. Qian, X. Li, J. Shen, Color centers and charge state change in Ce:YAG crystals grown by temperature gradient techniques, J. Cryst. Growth 286 (2006) 476-480. 
[23] Y. Shen, X. Feng, Y. Shi, A. Vedda, F. Moretti, C. Hu, S. Liu, Y. Pan, H. Kou, L. $\mathrm{Wu}$, The radiation hardness of Pr:LuAG scintillating ceramics, Ceram. Intern. 40 (2014) 3715-3719.

[24] S.R. Rotman, C. Warde, H.L. Tuller, J. Haggerty, Defect-property correlations in garnet crystalsV. Energy-transfer in luminescent yttrium aluminum-yttrium iron-garnet solid-solutions, J. Appl. Phys. 66 (1989) 3207-3210.

[25] M. Nikl, V. Babin, J.A. Mares, K. Kamada, S. Kurosawa, A. Yoshikawa, J. Tous, J. Houzvicka, K. Blazek, The role of cerium variable charge state in the luminescence and scintillation mechanism in complex oxide scintillators: The effect of air annealing, J. Lumin. 169 (2016) 539-543.

[26] M. Fasoli, A. Vedda, M. Nikl, C. Jiang, B. Uberuaga, D. Andersson, K. McClellan, C. Stanek, Band-gap engineering for removing shallow traps in rare-earth $\mathrm{Lu}_{3} \quad \mathrm{Al}{ }_{5} \mathrm{O}_{12}$ garnet scintillators using $\mathrm{Ga}^{3+}$ doping, Phys. Rev. B 84 (2011) 081102(1)-081102(4).

[27] W. Chewpraditkul, L. Swiderski, M. Moszynski, T. Szczesniak, A. Syntfeld-Kazuch, C. Wanarak, P. Limsuwan, Scintillation Properties of LuAG:Ce, YAG:Ce and LYSO:Ce Crystals for Gamma-Ray Detection, IEEE Trans. Nucl. Sci. 56 (2009) 3800-3805.

[28] S.R. Podowitz, R.M. Gaumé, R.S. Feigelson, Probing grain boundaries in ceramic scintillators using X-ray radioluminescence microscopy, J. Appl. Phys. 111 (2012) 013520.

[29] J. Liu, X. Cheng, J. Li, T. Xie, M. Ivanov, X. Ba, H. Chen, Q. Liu, Y. Pan, J. Guo, Influence of non-stoichiometry on solid-state reactive sintering of YAG transparent ceramics, J. European Ceram. Soc. 35 (2015) 3127-3136.

[30] M. Nikl, A. Vedda, M. Fasoli, I. Fontana, V. Laguta, E. Mihokova, J. Pejchal, J. Rosa, K. Nejezchleb, Shallow traps and radiative recombination processes in $\mathrm{Lu}_{3} \mathrm{Al}_{5}$ $\mathrm{O}_{12}$ :Ce single crystal scintillator, Phys. Rev. B 76 (2007) 195121.

[31] K. Brylew, W. Drozdowski, A.J. Wojtowicz, K. Kamada, A. Yoshikawa, Studies of low temperature thermoluminescence of GAGG:Ce and LuAG:Pr scintillator crystals using the T-max-T-stop method, J. Lumin. 154 (2014) 452-457. 
[32] A. Vedda, D. Di Martino, M. Martini, V.V. Laguta, M. Nikl, E. Mihokova, J. Rosa, K. Nejezchleb, K. Blazek, Thermoluminescence of $\mathrm{Zr}$-codoped $\mathrm{Lu}_{3} \mathrm{Al}_{5} \mathrm{O}_{12}$ :Ce crystals, Phys. Status Solidi A - Appl. Res. 195 (2003) R1-R3.

[33] S.Zhang, C. Li, R. Pang, L. Jiang, L. Shi, Q. Su, Long-lasting phosphorescence study on $\mathrm{Y}_{3} \mathrm{Al}_{5} \mathrm{O}_{12}$ doped with different concentrations of $\mathrm{Ce} \sim^{(3+)}$, J. Rare Earths 29 (2011) 426-430.

[34] A.G. Petrosyan, K.L. Ovanesyan, M.V. Derdzyan, I. Ghambaryan, G. Patton, F. Moretti, E. Auffray, P. Lecoq, M. Lucchini, K. Pauwels, C. Dujardin, A study of radiation effects on LuAG:Ce(Pr) co-activated with Ca, J. Cryst. Growth 430 (2015) $46-51$. 